\title{
Growth of Creative Capital and Human Perspectives under the Conditions of Globalisation
}

Lyudmila M. Andryukhina, ${ }^{+*}$ Yevgeniy Dorozhkin, ${ }^{\dagger}$ Alexander Kislov, ${ }^{\dagger}$ Nataliya Senognoeva, ${ }^{\dagger}$ and Pavel Kolobkov ${ }^{+}$

\section{Abstract}

Growth of creative capital and ever-burgeoning interest in the creativity phenomenon appear to have been facing intimidation with new threats emerging in connection with them - the unpredictability whereof is increasing under conditions of globalisation. The purpose of this study is to analyse the possible negative consequences of human creativity, globalisation and technological development. This perspective is developed using methods of comparative theoretical and methodological analysis, methods of theoretical reconstruction of basic strategies of the creative capital formation, modelling and extrapolation methods.

The issues of essence, nature, creativity and creative capital should be discussed in connection with solving social problems and studying of perspectives of human development. This is important because the human creation and creative activity can lead both to constructive and destructive processes, such as Human Development and Human disappearing from the history scene due to their own creativity.

The proposed perspective substantiates the necessity of deepened theoretical-philosophic analysis of creativity and growth of creative capital in connection with the emerging threats of the human development- discloses new aspects of the topic under discussion, which did not receive sufficient coverage in the scientific literature. Conclusions of the study possess a practical meaning for substantiating the development strategies in various fields of social practice and education in terms of globalisation.

Keywords: Creative Capital; Transhumanism; Justification of Creativity; Human Perspectives; Globalisation

\footnotetext{
${ }^{\dagger}$ Russian State Vocational Pedagogical University, Russian Federation

${ }^{*}$ Corresponding Author, Email:andryuhinalyudmila@rambler.ru

(C) 2020 Andryukhina et al. This is an Open Access article distributed under the terms of the Creative Commons Attribution License (http://creativecommons.org/licenses/by/2.0), which permits unrestricted use, distribution, and reproduction in any medium, provided the original work is properly cited.
} 


\section{Introduction}

At present, successful fulfilling of the innovation development scenario is directly connected with many countries via the necessity of growth of the society's and personality's creative capital, which is demanded both from workers and from industries so that to form the economic system, in which the economy will be based on producing innovative ideas and thus be defined as the creative economy (Batishchev, 1997; Andryukhina, 2012, 2014; Degtyarev, 2014; Davydova, Dorozhkin, \& Fedorov, 2016, 2018; Krayukhina, Shmakova, Smetanina, Nikolaeva, \& Tershukova, 2016; Vishnevsky, Narkhov, \& Didkovskaya, 2018; Zakirova \& Volodina, 2018).

The category-conceptual apparatus of the creative economy conception has begun developing actively from the beginning of the 21st century and consists of such concepts as "creative ethos", "homo creativus", "creative industry", "creative class", "creative society", "creative cluster", "creative space", "creative city", "creative capital" and many other similar ideas (Florida, 2005). Thus, creativity is among the most important assets in the modern world. At the same time, the fact that the growth of creative capital can be associated with the growth of social threats and other forms of hazards in the increasing connectedness of the global world has been studied very little. Indeed, the issues of essence, nature, creativity, and creative capital are relevantly discussed in connection with solving social problems and with studying perspectives of human development. This perspective aims to outline the growth of creative capital and human perspectives in an increasingly globalised world. It begins with a brief review of the literature. Following this, it describes the methods and the final sections critically discuss the findings.

\section{Literature Review}

As specialists put it, the process of substitution of physical and natural capitals by human capital (HC) in developed countries' national welfares and the overwhelming predominance of investments in $\mathrm{HC}$ over investments in physical capital-are the peculiar processes of the last half of the 20th Century and the 21st Century (Florida, 2005). Leaning on the human capital theory, Richard Florida came to the conclusion about the necessity to develop the "creative capital" theory (Florida, 2005). Earlier, in a similar context, The Nomura Institute researchers singled out the four époques in the world economic development: agricultural, industrial, informational and creativity Epoque (Batishchev, 1997). Creative capital is an important part of the modern economy. There are several basic concepts that define creative process:

Organisational concepts - the essence and matters of creativity development are regarded in application to organisations, basing on intraorganisation problems and with purpose of searching for strategies of organisations' growth and successfulness (Handy, 2001; Nonaka, 2003; Senge, 2003; Amabile, 2006; Asstlin \& Thai, 2007; Cook, 2007; Shevyrev, 2007; Pechnikov, Prenzov, \& Mashoshina, 2018).

Social (or socio-cultural) conceptions of creativity: the source of creativity is seen not in so much inside organisations but outside them: in online networks, discourse, various types of social community (creative class, practice-based communities) and technologies, in social and definitely formed socio-cultural spaces (uncertainty states) and even in a particular type of time (period of change): Florida (2005) creative class, Handy (2001) - inconsistent changes as a base of creativeness), Landry (2005) - creative industries (Dubina, 2000; Vanyurikhin, 2001; Vishnevsky, 2018).

Technological concepts: the essence of creativity is disclosed as a certain technology or a total of thinking technologies, solving problems, restructuring of mental maps, work on the level of NLP technologies, etc.; unlike the previous group of concepts, they are eligible for wide application and searching of certain universal algorithms and systems of creation (Altschuller, 1979; Bono, 1997; Dilts, 2003; Alder, 2004). 
Event-based concepts: creativity is understood as an event, and to make this event accomplished, definite conditions shall be needed. From this point, it is essential to reveal and possibly systemise these conditions, to learn how to reproduce them in order to create stable creativity states. Belonging to these conditions can be habits and competencies of overcoming barriers, the man's spiritual self-development, the whole system of management which in this case will be referred to as creative management, work aimed at arranging of creative teams, support of innovative leaders, development of creative resources (coaching), etc. (Downey, 2005; Amabile, 2006; Cook, 2007; Gogats, 2007; Asstlin \& Thai, 2007).

Thus, creative capital forms added value and social value (as indicated above) in the processes of production, distribution, exchange and consumption.

Today, however, especially in the scientific literature, perception of creation has been indurated with the plus sign only (Florida, 2005), as the progress of human society is possible, first of all, if there are no barriers to human creativity.

However, the man's creative work and creative activity can result in both constructive and destructive processes, such as human development and human disappearing from the history scene due to their own creativity, however paradoxical it may sound.

Globalisation has engulfed all the spheres of public life and the phenomenon of global economy has emerged (Begichev, Galushkin, Zvonarev, \& Shestak, 2019). Globalisation has a two-fold character. Along with the spread of technological progress and the cross-border movement of the capital, the global economy has faced ethical problems amid the desire of business entities to monetise most social relations.

Ethical issues caused by globalisation are aspects of human-technology interaction. Modern society has to determine the rules for such interaction and the methodology for resolving conflicts between humans and artificial intelligence (Shestak \& Volevodz, 2019). The ethical nature of the problem implies the need to form the "rules of the game" in updated social relations, where robots and artificial intelligence are full-fledged members of society with specific functions and roles.

Creativity, being the basis of science and a driver of development, becomes a zone of concentration of human-technology conflict, stimulating the emergence of new forms of humanism and ethical standards of a global society.

Only a few authors (Batishchev, 1997; Buzgalin, 2015a; Shevyrev, 2007) see the contradictory nature of creativity and, among other things, analysis of its destructive forms as the central point of their studies. As Batishchev wrote, "one should not no longer uncritically reproduce a very wide-spread view of today that creativity as such possesses its "nature-bestowed" warrantied positiveness." (Batishchev, 1997: 320).

Creativity can maintain its "plus" sign only in harmony with the higher, absolute values of global society, while disharmony leads to changing it into the opposite "minus". An interlinking of creative possibilities, the growing creative capital and value-based foundations determines perspectives of the human development and thus becomes especially relevant today.

This study, being a descriptive one, deploys a number of methods - comparative theoretical and methodological analysis, methods of theoretical reconstruction of base strategies of the creative capital formation, modelling and extrapolation methods. The results are illustrated in the following section.

\section{Results}

The matter of distinguishing between "creativity plus" and "creativity minus" is extremely complicated and cannot be subjected to rational-logical analysis to full extent, as these variables can be defined differently, especially when it comes to defining negative and ambiguous consequences of creativity (Kislov, 2012). The difficulty consists in the fact that the result (as well as the process) of creative activity 
in various periods can be very different. During one period, tasks of deconstruction of the old are mostly solved; during other periods there remains the need in establishing new structures, practices and even traditions. Thus, for instance, it would hardly be right to exclude processes of the building of organisational structures, the system of justice, the invention of "management machines" (e.g. bureaucracy) or social institutes from the creative sphere. It is obvious, though, that as times passes the discovered and established new structures become ossified and begin themselves to restrain creative processes, so the need for their deconstruction and change becomes necessary. Today, globalisation serves as the primary catalyst for renewal.

But here it is interesting to conduct the purely phenomenological analysis, specifically in fixation of those forms of creative activity in the modern society which are evaluated in various forms as bearing a threat to the humans and society. "Under modern conditions when the creative activity becomes the most important component of labour productivity growth (and thus a necessary component of the modern material production), perverse forms of creation begin to develop too, with the objective necessity" (Buzgalin, 2015a: 189).

The latter includes not only the entire sphere of anti-creation but also totalities of mechanisms which characterize the use of the man's creative potential in a perverse sector (from the mass culture and professional sports to labour of programmers in headquarters offices of financial corporations)" (Buzgalin, 2015b: 331). This sector is characteristic of a kind of pseudonovelty. The essence of the consumerist society causes the never-ending chase after novelty as such. "Pseudo-novelty of such a kind is characteristic not only for the production of goods and services on the market. It is typical for producing the semblance of new services in the mass culture sphere, for creation of a semblance of new ideological settings in the field of spiritual production, etc." (Buzgalin, 2015a: 520). "Today a significant (if not predominant - again, one has to work with the statistical data) part of those who are referred to as "creative class" are busy in branches which are useless or even harmful for the society and the Man. Designers of new types of weapons and "anti-terrorist" technologies, "new" types of elite cosmetics and blockbusters, mass media "news" and video clips, plus financial profiteers, brokers, dealers, marketing consultants, etc. - all these superprestigious and "super-creative" figures of the modern world, as well as really talented IT professionals, painters, scientists, teachers, etc. who provide services to the former - all of them are needful for corporate capital only." (Buzgalin, 2015b: 179).

At the same time, the lifestyle, models of consumption, prestigious forms of selfpresentation, leisure activities, etc. which are artificially preset do not work for the development of the man in the creative or even any other actually significant social selfrealisation.

One can accept or deny this position, but it is evident that the creativity spiral is sublimated in the social space of simulacra wherein the human begins to lose senses of his/her existence behind the flow of pseudo-innovations.

Another "dividing line" between "creativity with a plus sign" and that "with a minus sign" appears with development of a new technological platform, with possibilities and perspectives of applying latest technologies.

The new reality, which is being created by telecommunication means requires comprehension by opening new perspectives. Here, it can be singled out in two approaches: on the one hand, it is humanism from positions of which opening technological aspects are connected with new possibilities of the man's self-realisation by disclosing his creative potential, developing new forms of social behaviour, culture, briefly speaking, with the philosophic concept of abundant life. On the other hand, the movement of transhumanism sets its aim to change a biological body and ensure prolongation of life, up to immortality, and thus create a new civilisation with new rules for human-technology interaction. 
In the framework of humanism, critical perception of the Cartesian paradigm is actualised wherein many authors see a source of modern cybernetic trans-mutational mythologies. Beginning from Descartes, his dividing of the world into the extension and the thinking, the man's figure is located eccentrically concerning the world and boiled down to a purely intellectual bodiless (and extra-social, it is needed to be added) creature. The Cartesian oblivion of the human body, reducing of the man's role to an epistemological subject which derives senses and produces knowledge, today finds its logical continuation in metaphysics of virtual existence where neither social nor corporal and no any other peculiarities of a real man are becoming immaterial. On the other hand, as a counter to the Cartesian paradigm, today one can witness active interest of philosophy to the themes of the body, the landscape and the comprehension of the multidimensional character of the human being topology, its external, spatial configurations, and manifestations. Philosophic special concepts of real human presence are actively developed at present (Gumbrecht, 2006; Lichtman, 2011; Andryukhina, 2014).

However, the philosophic concept of presence, with all its indisputable significance, is not sufficient already and cannot, to our mind, become an exhausting base for affirmation of humanistic positions in front of the growing discourse of cybernetic dehumanisation. As soon as another breakthrough in the IT-sphere occurs, a very quick re-denotation of all which is connected with the human reality will occur (Davydova et al., 2016).

Specialists began to use the concept of "telebeing". Yet this very concept has just intensively drawn in cybermythologies pictures of the so-called "release of the man" from allegedly oppressing forms of the earthly life. Mark Dery (2008) in his book Release Velocity: Cyberculture at the End of the Century (the literal formulation of the incorrect translation of the title of the book in Russian is Escape Velocity: Cyberculture at the End of the Century) examined various subcultures of the information Epoque quotes alongside numerous variants of such mythologies. Among them are cyberspace, schismatrix, final transcendence, post-human revolution, and telebeing. Terence McKenna immerses in fantasies how in the virtual reality "men and women are shedding off monkey's bodies and becoming virtual octopuses swimming in a silicon sea" (Dery, 2008: 112). By this statement, he implies octopuses' computergenerated bodies are perfectly suited to the post-Logos paradise, as McKenna sees the virtual reality in his mind. An octopus, he ponders over, "does not convey its linguistic content, it becomes its linguistic content itself" (Dery, 2008: 114) while communicating with other octopuses using the body and colour language". Our lot, like that of an octopus, is to be converted into what we think, to allow thoughts to penetrate our bodies and to allow our bodies to become the thought" (Dery, 2008: 117). McKenna writes "and the virtual reality will help us in this, as electronics is able to convert verbal utterances into visual colour images <...>. At last, we will see our thoughts indeed" (Dery, 2008: 119). TeleBeing is a vivid example of the implementation of the "event" concept of creativity, which is transformed into a social concept since TeleBeing might fundamentally change social relations, communication and interaction between people.

Hans Moravec, an artificial intellect theoretician, tries to persuade us in cold blood that we are staying on the threshold of the "post-biological" world and that from mechanical forms of life endowed with intellect and capability of selfreproducing "organisms will grow out which are not a halfpenny lower in complexity of organization than we are" (Dery, 2008: 132). "Very soon", Dery believes "we all will upload our souls into computer memories or robots' bodies and thus forever will give up on our helpless flesh" (Dery, 2008: 143).

Within the comprehension of Stelarc (Stelios Arcadiou by birth), the most prominent representative of the cyberpunk body art, a post-man, bowelled and stuffed with easily replaceable modular components, stretched over with iron muscles of an exoskeleton. It is 
equipped with a lot of antennas which increase his eyeshot and hearing and furnished with a brain implant or a genetically modified brain which is at par with a supercomputer in its properties. Such a post-man will possess "panplanetary" physiology: strong, flexible and able to function in any atmospheric conditions, under different gravitational pressures and electromagnetic fields. Organisms of such a kind can be re-designed and converted into space researchers, Stelarc concedes. However, according to the scenario presented by him in most of his published articles and public lectures, mutated and transmigrated remnants of the human race acquire peace in the virtual reality "absolutely veracious illusion of TeleBeing" wherein their "working parameters will be limited by neither physiology not location in space" (Dery, 2008: 100). Such robots will primarily solve the problems and needs of humankind, which will come out of their technological concept of creativity. However, society will also need to adapt to such changes. Robots are to be transformed into full-fledged members of society, thereby, influencing the principles of the international division of labour, migration flows, communication between participants in public life. Thus, robotisation has the prospect of development in the context of the social concept of creativity.

Indeed, the creative activity will be able not just to discover new possibilities for humans but also set a boundary to development.

Taking into account of these things, which just yesterday were regarded as fantastic tales, are converted into scientific hypotheses with an increasing velocity today, can become routine reality tomorrow, however, it has to be admitted with responsibility (Kislov, 2012; Andryukhina, Dorozhkin, Poliakova, Zaytseva, \& Ovchinnikov, 2017) that Homo creativus is immeasurably higher than that of Homo economicus, and possibly higher than it was in other époques.

\section{Discussion}

Growth of creative capital and creativity cannot be stopped. More and more are actually becoming studies of social deformations of creativity which lead to the substitution of genuine creativity by its simulacrum, and they are seen as an increasing threat to the humankind (Zeer, Yugova, Karpova, \& Trubetskaya, 2016). What can the humankind expect: new possibilities, disclosing of creative potential, development of new forms of sociality and culture, or "overcoming the human nature" and creating "the post-man" or "super-man", at the expense of releasing from the biological body or even bereaving of a usual human appearance and the very essence of the man, as it is predicted by transhumanism ideologists?

It is possible for a person to find innovative solutions to existing problems if there are no barriers to creative activity. Both domestic issues and global crises are to be optimised. However, few people in the research world focus on the fact that simplifying human life might cause the loss of many skills (Pechnikov et al., 2018) that a person needs for physical survival (a person will simply forget how to organise his/her life activities independently). A desire for creative transformations at the level of individuals might also be gradually reduced, where it will be replaced by the individualistic strategy of consumption of innovations and technologies.

Globalisation has turned the modern world into a single ecosystem, where everything is interconnected.

As we tried to demonstrate, currently, it is especially important not just to move farther and farther in mastering techniques and technologies of creativity, but also, aiming at preventing potential threats-one has to address to the analysis of social and humanistic bases (Zeer et al., 2016, Davydova et al., 2018) of the growth of creative capital. The philosophical, cultural-anthropological view on the nature of creativity is needed. As we think, Batishchev, a Russian philosopher (1997: 46), could discern this fine complicatedness of the creativeness issue and necessity of the special mental space at approaching to comprehending thereof." Philosophic comprehension of creation", Batishchev (1997: 202) wrote:

differs from all special approaches thereto... Such comprehension is aimed at solving the matter of how the correct 
understanding of creativity is possible in its inner, profound sense-based content, by bringing up comprehending of this matter to its juxtaposition with the question about how it is possible and what should be the man's creativity in its relation to potentials of the whole boundless objective dialectic existing in the Universe. Thus, the philosophical approach is, on one hand, decidedly theoretical-cognitive, gnoseological, fully mediated by reflection over principal possibilities and perception; but, on the other hand, this very mediatedness translates understanding as encountering of similar with the similar into the ontological plan. The question about how to make creativity an object of the external subjective comprehension will outgrow into a more profound and all-inclusive question: how the subject himself can be creative, be worthy of creativity, and how to objectively substantiate his own will to it (Batishchev, 1997: 194).

\section{Conclusion}

The modern world tremendously expanded possibilities of access to information - made forms of its receiving more perfect, cancelled many social intellect institutions earlier via restriction of data exchange (wherein processes of overcoming bureaucracy and ideological machines are included). It set the task of creative processing of information to the human intellect, similarly to work processing of prodigious ore deposits (information as a new resource) to create (a new guiding motif) an intellectual, commercial product sought for by creative economy. Thus, it is not by coincidence that today they say more frequently about the transition from the rationality age to the creativity age. As a prerequisite, creativity requires reliance on the whole intellect, to be more exact, on a human's integral intellectual forces, not just on logic and reasoning. Besides, hopes are growing up for controlling the chaos of creativity by methods and methodology (from the position of creative process control, its regulation, and controllability of the content); restraining of the human brain and making it somehow manageable might lead to a partial success in minimising the negative consequences of creativity. Conjugated in the modern culture would occur both possibilities of releasing of the man's creative forces - and new threats of univariate use of these forces; both the man's ascension and perfecting - and the doubt inability to subordinate the generated creative technologies, new torrents, and powers of life.

The current study substantiates the necessity of deepened theoretical-philosophic analysis of creativity and growth of creative capital in terms of globalisation in connection with the emerging threats of the human development-discloses new aspects of the topic under discussion which have not received sufficient coverage in the scientific literature. The conclusions of the study possess a practical meaning for substantiating of development strategies in various fields of social practice, the field of education included.

\section{References}

Alder, H. (2004). CQ, or Muscles of Creative Intellect. Moscow: Fair Press.

Altschuller, G. S. (1979). Creativity as Exact Science. Moscow: Sov. Radio.

Amabile, T. (2006). How to Kill Creative Initiative. In J. Henry (Ed.), Creative

Management and Development (pp. 9-36). SAGE Publications Ltd. http://dx.doi.org/10.4135/9781446213704.n2

Andryukhina, L. M. (2012). Cultural Topology of Creativity. The Education and Science Journal, 3, 3-16. https://doi.org/10.17853/1994-5639-

2012-3-3-16

Andryukhina, L. M. (2014). Telepresence technologies as a new anthropological platform for education development. The Education and Science Journal, 8, 49-66.

https://doi.org/10.17853/1994-5639-2014-8$49-66$

Andryukhina, L. M., Dorozhkin, E. M., Poliakova, M. V., Zaytseva, E. V., \& Ovchinnikov, V. I. (2017). Emotional Leadership in Creative 
Organizational Healthcare Practices.

International Journal of Advanced

Biotechnology and Research, 8(4), 1250-1261.

Asstlin, C., \& Thai, A. (2007). La Creativite ne s'invent pas, elle se manage! Paris: Les Editions Demos.

Batishchev, G. S. (1997). Introduction into the dialectics of creation. St. Petersburg: RHGI Publishers.

Begichev, A. V., Galushkin, A. A., Zvonarev, A. A., \& Shestak, V. A. (2019). History of the creation and activities of the League of Nations. Voprosy Istorii, 9, 108-113.

Bono, E. (1997). Lateral Thinking. Saint Petersburg: Piter.

Buzgalin, A. B. (2015a). The global capital. In 2 volumes. Vol. 1 Theory. Global hegemony of the capital and its limits ("The Capital" re-loaded). Revision 3, corrected with significant addenda. Moscow: Lenand.

Buzgalin, A. B. (2015b). Global capital. In 2 volumes. Vol. 2 Theory. Global hegemony of the capital and its limits ("The Capital" re-loaded). Revision 3, corrected with significant addenda. Moscow: Lenand.

Cook, P. (2007). Best Practice Creativity. Minsk: Grevtsov Publisher.

Davydova, N. N., Dorozhkin, E. M., \& Fedorov, V. A. (2016). Innovative process development in the framework of scientific educational network: Management model. Naukovyi Visnyk Natsionalnoho Hirnychoho Universitetu, 5, 157163.

Davydova, N. N., Dorozhkin, E. M., \& Fedorov, V. A. (2018). Educational research networks principles of organization. International Journal of Engineering \& Technology, 7(2.13), 24-29. https://doi.org/10.14419/ijet.v7i2.13.11573

Degtyarev, S. N. (2014). Development and implementation of creativity-oriented teaching strategy. The Education and Science Journal, 6, 20-34. https://doi.org/10.17853/1994-56392014-6-20-34

Dery, M. (2008). Escape Velocity: Cyberculture at the end of the century. Moscow: AST.
Dilts, R. (2003). NLP: Creativity Management. Saint Petersburg: Piter.

Downey, M. (2005). Efficient Coaching. Lessons from Coaches Trainer. Moscow: Dobraya Kniga.

Dubina, I. N. (2000). Creativity as Phenomenon of Social Communications. Novosibirsk:

Publishing House of Siberian Division of the Russian Academy of Sciences.

Florida, R. (2005). Creative class: People Who Change the World. Moscow: Klassika-XXI.

Gogats, A. (2007). Business + Creative =. Minsk: Grevtsov Publisher.

Gumbrecht, H. (2006). Production of presence. What cannot convey the meaning. Moscow: New Literature Review.

Handy, C. (2001). The Age of Unreason. Saint Petersburg: Piter.

Kislov, A. G. (2012). Education versus Creativity: The Origins of Demystification. The Education and Science Journal, 1(9), 90-105. https://doi.org/10.17853/1994-5639-2012-990-105

Krayukhina, O. E., Shmakova, L. E., Smetanina, V. Y., Nikolaeva, E. A., \& Tershukova, M. B. (2016). Activation of Learning and Creative Activity of the Vocational Pedagogical University Students. International Journal of Environmental and Science Education, 11(15), 8311-8322.

Landry, C. (2005). The Creative City. Moscow: Klassika-XXI.

Lichtman, H. S. (2011). What is Telepresence? Telepresence Options, Spring. Retrieved from http://www.webtorials.com/main/resource/pa pers/telepresence/paper1/What-Is-

Telepresence.pdf

Nonaka, I. (2003). Company as Creator of Knowledge. Origination and development of innovations in Japanese firms. Moscow: OlympBusiness CJSC.

Pechnikov, A. N., Prenzov, A. V., \& Mashoshina, A. A. (2018). The features of processes of skills (special competencies) formation. The Education and Science Journal, 20(1), 9-53. 
https://doi.org/10.17853/1994-5639-2018-1-9- Vishnevsky, Y., Narkhov, D., \& Didkovskaya, Y. 53 (2018). Trends in higher vocational education:

Senge, P. (2003). The Fifth Discipline: Art and Practice of a learning organization. Moscow: Olymp-Business CJSC.

Shestak, V. A., \& Volevodz, A. G. (2019). Modern requirements of the legal support of artificial intelligence: a view from Russia.

Russian Journal of Criminology, 13(2), 197-206. https://doi.org/10.17150/25004255.2019.13(2).197-206 professionalization or deprofessionalization? The Education and Science Journal, 20(1), 152170. https://doi.org/10.17853/1994-5639-20181-152-170

Zakirova, A. F., \& Volodina, Y. N. (2018). Trends and Prospects in Educational Modernisation: $\mathrm{A}$ Hermeneutic Approach. The Education and Science Journal, 20(9), 9-34. https://doi.org/10.17853/1994-5639-2018-9-9Shevyrev, A. V. (2007). Creative Management: Synergetic Approach. Belgorod: LitKaraVan. 34

Zeer, E. F., Yugova, E. A., Karpova, N. P., \& Trubetskaya, O. V. (2016). Psychological Vanyurikhin, G. I. (2001). Creative Management. Management in Russia and Abroad, 2, 122-143 Predictors of Human Hardiness Formation. International Journal of Environmental and Science Education, 11(14), 7035-7044. 